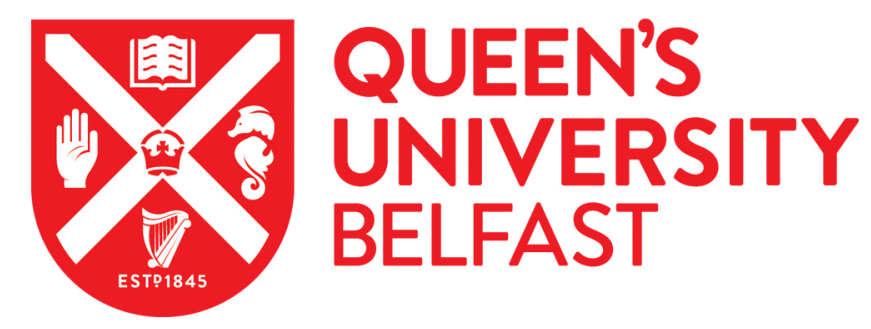

\title{
A study of the operationalization of management controls in United Kingdom Private Finance Initiative contracts
}

Connolly, C., Ahmad, S., \& Demirag, I. (2020). A study of the operationalization of management controls in United Kingdom Private Finance Initiative contracts. Public Administration, 98(1), 92-108.

https://doi.org/10.1111/padm.12401

Published in:

Public Administration

Document Version:

Peer reviewed version

Queen's University Belfast - Research Portal:

Link to publication record in Queen's University Belfast Research Portal

Publisher rights

Copyright 2018 Wiley. This work is made available online in accordance with the publisher's policies. Please refer to any applicable terms of use of the publisher

\section{General rights}

Copyright for the publications made accessible via the Queen's University Belfast Research Portal is retained by the author(s) and / or other copyright owners and it is a condition of accessing these publications that users recognise and abide by the legal requirements associated with these rights.

Take down policy

The Research Portal is Queen's institutional repository that provides access to Queen's research output. Every effort has been made to ensure that content in the Research Portal does not infringe any person's rights, or applicable UK laws. If you discover content in the Research Portal that you believe breaches copyright or violates any law, please contact openaccess@qub.ac.uk. 


\title{
A study of the operationalization of management controls in United Kingdom Private Finance Initiative contracts.
}

\begin{abstract}
Utilizing evidence from a United Kingdom (UK) road case study Private Finance Initiative (PFI) project, this paper considers how the UK central government's infrastructure strategy is operationalized through accounting-based performance measures and incentive systems, and articulates how the adoption of such systems is moderated by trust practices. The findings indicate that initial government policy objectives, translated as performance indicators in the case study, failed to offer adequate incentives for contractors and created tensions. However, controls were later developed through inter-party trust practices for managing performance and relational risk. These findings have important implications for PFI policy and practice, including that negotiation can: (i) lead to pragmatic controls being introduced to foster cooperation and trust-building; and (ii) provide opportunities for adapting the monitoring and incentive mechanisms. This study also contributes to previous literature where PFI control systems were largely regarded as inadequate for dealing with unforeseen conflicts between parties.
\end{abstract}

Keywords: Private Finance Initiative (PFI), Public Private Partnerships (PPPs), Accounting, Management controls, Performance measurement, Trust.

\section{INTRODUCTION}

The recent financial crisis encouraged governments globally to introduce policies designed to reduce public spending (Heald and Steel 2017). Initiatives ranging from outright sale (privatization) to mixed/hybrid models of public service delivery can be traced back to the 
1980s (Warner and Bel 2008; Alonso et al. 2015). However, it is contended that mixed/hybrid models have come to the fore recently because privatization is no longer politically viable or because neither the pure-public or pure-private route has emerged as the natural choice (Warner and Bel 2008; Florio 2014). Perhaps the most well-known mixed model variant for public service delivery is Public Private Partnerships (PPPs) (Sclar 2015). In Europe, there have been more than 1,000 PPP-based (infrastructure) projects, with their capital value of approximately US\$635 billion representing around half of total PPPs world-wide (Public Works Financing 2011; Lamman et al. 2013). Internationally, the United Kingdom (UK) remains one of the largest PPP actors in terms of the number and capital value of projects (KPMG 2010; European PPP Expertise Centre 2013).

Ideologically, private sector involvement in public infrastructure and service delivery was driven by a belief in the superiority of the sector's management approaches. This phenomenon, labelled New Public Management (NPM), emphasises the development of competition (e.g. quasi markets) for public service delivery and the use of extensive control regimes by the procuring authority to incentivize the service-delivering organizations to achieve targets set by the former (Diefenbach 2009; Florio 2014; Alonso et al. 2015). Thus, NPM places the state in a supervisory (principal) role vis-à-vis private infrastructure and service delivering organizations (agent) (Sclar 2015). While a belief in NPM rationalities could be one reason for governments to introduce PPPs (Broadbent and Laughlin 2005), other factors could be politically-motivated condemnation of public-sector competence and/or constrained public funds (Sclar 2015). Indeed, PPPs have spawned from a mixture of ideological, financial and political pressures, with the policy being 'clothed in different garments' (Greenway et al. 2004).

Regardless of the motivations, PPPs lock the state into long-term contracts, with a fundamental issue facing the principal (state) being mission misalignment since the private 
partner's primary interest is investment returns (Sclar 2001). Moreover, PPPs possess a contextual and dynamic nature which could necessitate change management and contract renegotiations over their operational life (English and Baxter 2010). Furthermore, as the contracts are written a priori, they are invariably imperfect as it is impossible to incorporate clauses which address all potential operational and relational contingencies (Sclar 2015). Thus, compromise and negotiation are essential for contracts to function operationally. Given the challenges facing the state in governing PPPs, by focusing on a single road case study PFI project (hereafter 'RCSP'), this paper articulates how project-level accounting-based controls and trust practices are enacted for governing the operations and inter-party relationships over the operational life cycle. Although, while it is difficult to determine the extent to which the findings from this RCSP can be generalized, Nisar (2007) argues that case study research enables an evaluation of key findings and emerging ideas by providing an opportunity for the intensive analysis of specific details often overlooked by other methods. Thus, these findings offer substantial empirical evidence to aid our understanding of the management and governance of PPP contracts, an area that has experienced limited scholarly inquiry (Steijn et al. 2011; Chung 2016; Caperchione et al. 2017).

In terms of structure, the next section provides the theoretical underpinnings for the empirical analysis. Then, the background to the RCSP, including the research methods, is described. The subsequent two sections present the empirical findings and the paper's theoretical contributions, policy implications and avenues for further research.

\section{THEORETICAL UNDERPINNINGS}

In the UK, the term PFI ${ }^{\mathrm{a}}$ commonly refers to a PPP, with the transport sector of roads being the lead PFI adopter when it was officially launched in 1992 (Edwards et al. 2004). However, little attention has been devoted to the evaluation of operational roads PFI projects (Shaoul et 
al. 2007). Also, internationally, as this sector is the highest recipient of private finance (Public Works Financing 2011; Yehoue 2013), it is an important area to research. When this study was conducted, there were 12 operational PFI contracts under the UK Highways Agency $(\mathrm{HA})^{\mathrm{b}}$, with a combined capital value of almost $£ 2.5$ billion (HA 2015).

NPM-inspired policies have contributed to a more commercial-style approach to publicsector governance with increased emphasis on value-for-money (VFM) (Coulson 2008; Demirag and Khadaroo 2008). This has impacted upon the structures and processes of accounting-based management controls with, inter alia, increased performance monitoring and incentives regimes (henceforth $\mathrm{MCS}^{\mathrm{c}}$ ) to enable government to control service-delivery organizations and employees (Diefenbach 2009).

Accounting technologies such as MCS serve as a means for operationalizing local policy objectives (Khadaroo 2014; Walker 2016). Consequently, as evidenced by this special issue, there is a desire to consider the linkages between accounting and public administration research in order to (better) understand how accounting and MCS are intertwined in public policy operationalization, together with the consequences for the public (taxpayers) (Kurunmäki and Miller 2011). Marques et al. (2011) note that within complex public-sector network organizational forms (e.g. PFIs), operational issues are delegated to private contractors, with the government department having a coordinating role within the network. Thus, MCS through inscription and calculations (Robson 1992; Walker 2016) could enable the procuring department to 'govern' by providing mechanisms for monitoring the contractors' performance and incentivizing them to operate in accordance with the project's goals (Marques et al. 2011).

While MCS might provide guidance for service providers through appropriate feedback loops (Busco et al. 2006), influencing (shaping) their actions is achieved mainly through financial incentives (Compagni and Tediosi 2012). Indeed, since PFI's adoption, successive 
UK governments have supported performance-based unitary payments, including performance-related controls and incentives for risk-management and achieving VFM (Her Majesty's Treasury (HMT) 2003, 2007, 2008, 2012). However, little is known about the operational dynamics of this major public policy domain (Toms et al. 2011; Andon 2012; Demirag et al. 2012). Consequently, this research is important as MCS implementation is complex (Bevan and Hood 2006; Speklé and Verbeeten 2014). Indeed, NPM-driven performance-measurement and incentive regimes can bring about judgement biases and perceptions of unfairness or subjectivity if the performance measures and/or relative weight attached to awarding or sanctioning decision making is contested (Franco-Santos et al. 2012; Speklé and Verbeeten 2014). Thus, the primary aim of this paper is to articulate how MCS are operationalized in a RCSP and explore their impact on contractors' performance.

Given the long-term and complex nature of PFIs, the embedded MCS, which are usually structured a priori, could be subject to change following interactions between localized actors (English and Baxter 2010). Therefore, within the RCSP, the interactions between MCS, the actors whose behavior the MCS tend to mediate and 'trust practices' are investigated (Minaar et al. 2016). In this context, trust practices represent the routines involving inter-party collaboration and the expression of sentiments or aspirations to address MCS-related tensions. Thus, in contrast to most accounting research on accounting-trust relationships where trust is conceptualized as a method of (informal) control, with the focus being on the implications of its presence or absence on MCS (Free 2008), this research seeks to understand 'trust in the doing' (i.e. the routines, understandings and knowledge that become mobilized for developing the contractual and relational governance within the context of this case study). Accordingly, this paper also analyzes the trust practices that are enacted ('trust in the doing') between the government and private-sector partners in the RCSP to address MCS conflicts in order to achieve the project objectives. 


\section{THE CASE STUDY}

\section{Context}

The UK transport sector is chosen as the broader case study site given the significance of PFI spend in this area (Demirag et al. 2010), with the primary investigative area being a HA operational road PFI contract. Given some major UK PFI projects have failed and required government intervention in the transport sector (Shaoul et al. 2006; National Audit Office (NAO) 2009; Jupe 2011), this is a fitting focus. Moreover, since the UK has remained the largest actor in the international PFI market, with several European countries drawing on their experiences (Gerrard 2010), extracting academic, policy and practical lessons from a UKbased case study is potentially constructive (Steijn et al. 2011; Chung 2016).

Ross and Yan (2015) suggest that PFI is prevalent in the roads sector as there is relatively less need for large design changes. Moreover, in the UK, roads PFI have a stronger financial appeal than other sectors because of government guarantees for the HA's PFI obligations (Shaoul et al. 2006). Nevertheless, UK government policy rationales for roads PFIs have changed over time, shifting from developing a private sector roads operating industry through shadow toll-based contracts to obtaining congestion solutions, commuter safety and environmental concerns (Edwards et al. 2004; Shaoul et al. 2007). In particular, for strategic roads, reducing congestion and improving road safety are key policy objectives (Department for Transport 2000a, b, 2004). Also, MCS in UK roads PFIs, particularly the (payment-based) incentive regimes, have developed more stringent performance-related criteria (Shaoul et al. 2006, 2007), underpinned by an emerging government rationality of transferring and managing risks (Burke and Demirag 2015).

This RCSP captures one of the largest UK roads PFIs and was signed soon after the advent of financial crisis, thus making it apposite for analyzing how strategic objectives for 
the roads sector (i.e. reducing congestion and improving road safety) are operationalized through NPM-based regimes that predominantly involve performance monitoring and incentives. Additionally, this case study involves an elaborate control regime compared with other UK roads PFIs ${ }^{\mathrm{d}}$.

\section{Background}

This RCSP's rationale was that the underlying road (motorway) suffered high congestion levels, which created the potential for serious accidents and unreliable journey times (RCSP Business Case and publicly available official reports ${ }^{\mathrm{e}}$ ). Under the RCSP's terms, a single private sector contractor (hereafter 'Special Purpose Vehicle' (SPV)) was assigned responsibility for widening (construction) two sections of the motorway (approximately 40 miles), together with operations and maintenance over the contract's 30-year life for the entire road (approximately 242 miles, which also included certain bridges and tunnels). The HA has executive responsibility for managing the contract and the RCSP was operational when this research was undertaken.

As unitary payments during the construction phase are availability-based, the HA achieves VFM if the widening schemes are completed on-time and to-budget (HMT 2003). The operationalization of the project objectives (i.e. to reduce congestion and improve road safety) involves the HA mobilizing a complex arrangement of MCS in order to incentivize the private sector to meet a series of performance measures. After outlining the research methods, these issues are discussed below.

\section{Research methods}

Case studies are supported when the empirical objective is to analyze the day-to-day functioning of accounting in contemporary organizations (Humphrey and Scapens 1996). 
Because of their contextual and dynamic nature, Andon (2012) contends that the micro operations of PFI contracts should be researched using case study methodology. This study employs a qualitative case study methodology (Yin 2017), combining field-based interviews with archival data.

To understand the RSCP's contract management, particularly the control regimes, data was obtained from: (i) the RCSP Contract and the Business Case, which were obtained under a Freedom of Information Act (2000) request to the HA ${ }^{\mathrm{f}}$; (ii) the HA's online policy information on PFI roads procurement; (iii) HMT's and NAO's guidance on PFI payment mechanisms, contract and inter-party relations management; and (iv) other related publiclyavailable reports (Table A). The main subject of analysis within the RCSP contract was 'Schedule 18 - Contract and Performance Management' (hereafter 'Schedule-18'). This provides a detailed framework of the control regimes deployable during the RCSP's operations and maintenance stages including: (i) a breakdown of the project objectives into key performance indicators (KPIs); (ii) performance monitoring, including performance review meetings and incentives mechanisms; and (iii) mechanisms for dispute resolutions.

\section{Insert Table A here}

Subsequently, senior individuals at the HA and SPV were contacted to seek their views on the research questions. Eisenhardt and Graebner (2007) posit that interviews facilitate contrasting opinions to be obtained, while Bryman and Bell (2011) contend that semistructured interviews allow interesting areas to be explored, as was the case in this research. Moreover, interviewees in senior positions can be expected to have a broader perspective of the issues sought by the researcher (Spence and Rinaldi 2014). The meetings with the RCSP representatives complemented the document analysis, enabling a deeper understanding of the 
control and trust practices. During the interviews, some additional RCSP-related documents were supplied by the interviewees.

The interview questions were shaped by the literature and themes from the document analysis, with three main areas emerging: firstly, the use of PFI for procuring roads together with the effectiveness of the control regimes within roads PFI contracts; secondly, the operationalization and consequences (i.e. effectiveness or tensions) of the MCS within the RCSP contract for reducing congestion and improving road safety; and thirdly, the use of trust practices to achieve project objectives.

More specific (including confidential) RCSP-related documents were also obtained from the interviewees via email. As some of these documents were part of newly-developed strategic management tools emerging from trust practices, they facilitated an in-depth understanding of how key elements of MCS operated and were being (re)shaped by trust practices. Thus, the field-based interviews and supplementary documents enabled an understanding of 'trust in the doing', together with the MCS-related concerns of the public and private parties. The data was coded using qualitative data analysis software QSR-NVivo9.2.

Initially, four (semi-structured) interviews were conducted, two at the HA and two at the SPV (with each lasting approximately one hour). In both organizations, the interviewees included a senior official responsible for managing the RCSP and an accounts/finance official who dealt with the payment mechanisms. In the HA, the RCSP's contract manager (hereafter 'Contract Manager-HA') and two payment mechanism officials responsible for calculating SPV payments (hereafter 'Paymech Official-HA') were interviewed. At the SPV, it was the CEO (hereafter 'CEO-SPV') and the finance director (hereafter 'Finance Director-SPV'). The interviews were recorded with the interviewees' permission and later transcribed, with the transcripts being sent to the interviewees for validation. Two subsequent telephone interviews 
were undertaken, with each lasting approximately 45 minutes. One of the authors visited the RCSP on a number of occasions to observe how certain safety and congestion-related performance issues aligned with the themes emerging from the document analysis and interviews. Overall, the data collection, interviews and site visits were undertaken between 2012 and 2017.

Having outlined the background to the RCSP and the research methods employed, the next two sections present the empirical analysis.

THE USE OF MCS FOR OPERATIONALIZING GOVERNMENT'S OBJECTIVES IN THE RCSP

\section{Background}

An underlying principle for setting controls in PFI contracts is for procuring authorities to clearly specify project objectives in terms of outputs, with the contractor being incentivized to deliver against them (HMT 2007). Accordingly, there should be formal outcome controls that specify project objectives, monitor the contractor's performance against the targets and link consortium incentives to performance target attainment (Marques et al. 2011).

The RCSP's outcome controls (operations and maintenance) comprise three fundamental elements (Figure A): (i) performance indicators (PIs); (ii) performance monitoring; and (iii) performance management (incentives regime). Performance monitoring and reporting, together with the RCSP's performance management regimes (Figure A), particularly with respect to the project objectives of reducing congestion and improving road safety, are now discussed.

Insert Figure A here 


\section{Performance monitoring and reporting in the RCSP}

PFI guidance stresses that procuring authorities should establish performance monitoring and reporting regimes as these are instrumental for contract and payment management (HMT 2007). This is illustrated in Figure A by the dotted arrows that connect the performance monitoring, reporting and incentive regimes. The RCSP includes KPIs ${ }^{\mathrm{g}}$ for reducing congestion and improving road safety $\left(\right.$ Figure $\left.\mathrm{B}^{\mathrm{h}}\right)$.

The development of KPIs (Figure B) represents their long-term strategic nature, requiring investment for delivering safety and congestion improvement schemes over the contract's 30year life. From the data analysis, 'lane-availability' was identified as the most significant (day-to-day) KPI for reducing congestion as it incentivizes the SPV to avoid lane closure, lane narrowing or temporary speed limits when undertaking daytime life-cycle works on the project road (Figure A).

The RCSP contract gives the HA the right to assess the SPV's performance against the KPIs and requires the SPV to cooperate with the HA in conducting audits or inspections. Moreover, it establishes procedures for self-reporting by the SPV regarding performance failures, an important feature of RCSP performance monitoring (Figure A).

\section{Insert Figure B here}

The SPV produces monthly, quarterly and annual reports (Figure A), with Schedule-18 establishing the monthly report as the primary document for SPV performance monitoring. This contains performance information against 250-300 targets, with the performance achieved against each being color-coded. Moreover, it includes performance dashboards which provide graphical and bulleted information about performance against KPIs for all project objectives on a month-by-month rolling basis, together with three-month projections. 
The monthly reports are reviewed by the HA and SPV at a Monthly Management Review meeting (Figure A). The HA uses a scorecard approach for measuring the SPV's performance annually, called 'Proactive Management Review' (PMR). A PMR panel measures the SPV's performance against the broader project objectives, awarding a score which is linked to financial rewards (i.e. bonus payments) based on the panel's judgment about performance (Figure A).

Therefore, RSCP performance monitoring was enabled by accounting as a technology of inscription and calculation. Audits, ad hoc HA inspections, periodic SPV performance reports and Monthly Management Review meetings relied on accounting numbers to enable the HA to monitor a distant domain of affairs. A partnering organization's motivation to cooperate in achieving the network's objectives could derive from 'material interest', 'coercion or fear'j. Hence, (financial) incentives, linked to performance monitoring regimes, could motivate the private contractor to achieve the desired project goals (Marques et al. 2011). However, performance measurement systems can cause discord if applied over-zealously and/or where performance measures do not produce the intended goals (Meer-Kooistra and Vosselman 2000). Such issues are discussed later in the context of the RCSP.

\section{Performance management (incentives) regime in the RCSP}

The incentives for managing the SPV's performance against project objectives are nonfinancial and financial, and include penalties and rewards (Figure A). Their enforcement during the operations and maintenance stages, together with their effectiveness in incentivizing the SPV to reduce congestion and improve road safety (Figure B), is now explored. 


\section{Non-financial incentives in the RCSP}

Non-financial incentives are activated when there are performance failures by the SPV. The four non-financial incentives (Figure A) are presented in order of severity, and their classification from 1-3 should make the SPV wary about more severe consequences if the related under performance remains unrectified. Under the RCSP contract, the issuance of a warning notice or performance-points ${ }^{\mathrm{k}}$ by the HA leads to increased performance monitoring at the SPV's expense. Mechanisms for performance points are detailed in Schedule-18 which describes the performance areas that could cause the SPV to receive performance points (based on specified formulae). Performance points are considered an effective incentive for PFI contractors, with their implications alerting financiers (NAO 1998). The accumulation of performance points creates additional costs for the SPV as it has to comply with further monitoring requirements (at 500 points) or even lose the PMR-bonus (at 600 points). Moreover, if under performance or an obligation breach during the operations and maintenance stage remains unrectified and leads to the accumulation of more than 3,500 points, contract termination could result.

With respect to improving safety and reducing congestion through improvement schemes (Figure B), the SPV's failure to meet targets can lead to performance points being levied:

...[I]n case of Safety Action Plans... it's a performance point incentive. So, they [subcontractors] must deliver the Safety Action Plans to keep performance points down.... (CEO-SPV)

While the SPV managed its performance points, it disputed the underlying performance measures and how they were weighted and used for sanctioning. Thus, performance points were viewed as a source of inter-party tension:

...when you are trying to justify value-for-money, picking up performance points doesn't feel like value-for-money. So, that's been a tension right the way through. Some say it is a 
good tension; I don't think so because you are not working as a collective, you are not working as a team, you are working as two sides. (CEO-SPV)

Previous research indicates that performance points were only issued after warnings (Edwards et al. 2004). However, in this contract, performance points have been levied since the commencement of operations and maintenance services. Thus, it appears that the HA has become more meticulous about using contractual MCS following the failure of other transport PFI projects due to poor project governance (NAO 2010).

After being sanctioned, if the SPV fails to rectify the underlying breach within the stipulated remedial period, the HA can direct the SPV to perform certain actions, undertake the necessary rectification itself or engage others (Figure A). The SPV has to bear the costs incurred by the HA in taking such actions. The HA may also terminate the contract following a serious contractual breach (e.g. abandoning operations) or performance points exceeding the 3,500 threshold. However, termination must be evaluated in terms of costs and benefits, together with the availability of alternative service delivery mechanisms (NAO 2006).

While the RCSP's non-financial incentives have financial consequences for the SPV, performance-based payment mechanisms are central to PFI policy risk allocation strategies (see 'Theoretical Underpinnings'). The RCSP's payment mechanisms (Figure A), and their effectiveness in shaping the SPV's conduct towards achieving the objectives of improving road users' safety and reducing congestion, are now discussed.

\section{Financial incentives in the RCSP}

RSCP unitary-payments, which are paid monthly to the SPV, comprise three elements: (i) base-service amount; (ii) performance adjustments; and (iii) other (non-performance) adjustments. Performance adjustments, which represent the SPV's financial incentives, have six elements (Figure A), of which three (lane availability, route performance and unplanned 
event management) are monthly adjustments related to reducing congestion ${ }^{1}$. Of the remaining three, one relates to maintaining the 'road condition' (calculated monthly) and two (Safety Performance Adjustment (SPA) and PMR bonus) are calculated annually.

Lane availability and road condition are deductions, whereas unplanned event management and SPA are a (capped) deduction or bonus. The PMR bonus ranges from $£ 0.25$ $£ 0.75$ million per year and is payable if the SPV obtains a score of 2 or higher on the PMR scorecard (Figure A). Since contract commencement, no PMR bonus has been awarded which, consistent with Speklé and Verbeeten (2014), is a cause of frustration for the SPV as it believes the PMR scorecard unfairly reflects performance:

...if you look at the description under each of the boxes they are quite subjective. So, you have got subjectivity on top of subjectivity. For example, the score this year was 1.7 out of 4.0 ...that's like 4 out of 10. So, is the contract which you are seeing on the ground a 4 out of 10? Clearly not. So, there is a lot of interpretation needed to make this a reasonable statement of how good this contract is. There is work to be done. (CEO-SPV)

Having discussed the payment mechanisms in broad terms, the adjustments relating to the two primary project objectives of reducing congestion and improving road safety, together with whether they have achieved their goals by incentivizing the SPV to deliver against the KPIs (Figure B), are now considered.

\section{Payment-based incentives for improving road users' safety}

With respect to improving safety by reducing the number of serious accidents, the SPA is the only (financial) incentive operationalized (Figure A). This adjustment, while not specifically linked to the safety-related KPIs, is allied to the overall outcome (i.e. trend in KSI ${ }^{\mathrm{m}}$ accidents). Since operations and maintenance services commenced, the SPA is an annual deduction. The SPV expressed reservations about this formula as it compares RCSP KSI data 
with comparator roads:

...you can see they took $£ 4.0$ million off me. I didn’t do anything, it’s because they got the formula wrong. So that's a disincentive. (CEO-SPV)

Moreover, in terms of the SPA's effectiveness as an incentive for delivering safetyrelated action plans and improvement schemes (Figure B), the regime appeared not to empower the SPV because the measures to which it was linked were not totally controllable by the contractors. It was acknowledged that contractors had limited influence on controlling accidents:

I would far rather be incentivized for the things which I have influence over. So, I have influence over the way I manage the asset, the road surface, the bridges, the viaducts.... But the travelling public, I am not incentivized. (CEO-SPV) As a consequence, the HA capped the SPA.

While capping financial incentives could be a risk-management strategy for government, this may dis-incentivize the private sector to work towards long-term strategic objectives, such as delivering safety-related programs and improvement schemes (Figure B):

If you look at the Safety Performance Adjustment, that is capped at a $£ 1.0$ million plus or minus each year. Then you think 'what investment do they have to make in order to make a difference?' Perhaps they are actually better off not spending that money. (Contract Manager-HA)

The SPV acknowledged that the SPA's capped value was a disincentive:

...if they were giving us $£ 10$ or $£ 15$ or $£ 20$ million each year then I think you could see a big difference. (CEO-SPV)

The payment mechanisms, particularly whether lane closure deductions (Figures A and B) have been effective in incentivizing the SPV to reduce congestion, are now examined. 


\section{Payment-based incentives for reducing congestion}

With regards to reducing congestion, lane availability (Figure A) is the most significant financial incentive, with penalty deductions potentially amounting to $£ 5-£ 6$ million per year. Unlike road-safety KPIs, the SPV can influence lane availability for planned works. This may explain why the lane-availability deduction is uncapped as the payment mechanism incentivizes the contractors to avoid daytime maintenance. The SPV employed innovative methods to prevent lane closure or temporary speed limits:

On the $[x y z]$ bridge there are some very big expansion joints.... We worked out that if we were going to repair those it would cost something like a million pounds in closure charges. So, what we have done is design some ramps which go over the top of the road surface... and what we do then is work from underneath. So, the incentivization for us is to use innovation to deliver that. (CEO-SPV)

However, the payment mechanisms did not appear to incentivize the SPV to implement congestion-easing schemes (Figure B) as these require considerable investment which the payment mechanisms did not match. Moreover, similar to safety improvement schemes, as contractors viewed certain congestion factors as uncontrollable, the payment mechanisms failed to motivate the SPV to invest in congestion-easing schemes:

When it comes to looking at how you reduce congestion, it is a very difficult issue because there are many reasons why traffic gets congested. The extent to which the PFI company can influence that is a matter of conjecture.... We have no control over traffic signals. Next door is the Highways Agency and they control all the big gantries; we don't. So you have to ask yourself to what extent you can do anything to reduce it [congestion]. We can't do a radio or television advert, talk to the public, go on Twitter or Facebook. So, as you are a driver, I can't talk to you. So how am I going to affect congestion? (CEO-SPV) 
While performance points incentivized the SPV given their financial consequences, including the ultimate sanction of termination, overall, the RCSP MCS were perceived as a dis-incentive given their tendency to penalize rather than reward. While the HA capped some of the payment-based incentives (e.g. SPA) in recognition of the contractor's inability to influence the risk factors underlying outcome achievement, this proved a dis-incentive with respect to delivering long-term congestion and safety-related improvement schemes. Thus, the performance management regimes operated bureaucratically and without proper incentivization which limited their effectiveness. Therefore, the deployed MCS resulted in dissonance between the HA and the SPV (i.e. the contracting parties):

Do they believe that we will always act in their best interest? Do they believe that they are getting the best service? I feel that the answer to all that is 'no'.... So, I would say fundamentally this relationship will always be fragile. (CEO-SPV)

It was also observed that the operationalization of the performance monitoring mechanisms failed to provide opportunities for developing positive feedback loops and therefore reduced chances for improving performance:

If you look at the agenda of the Monthly Management Meeting, the way it is described in the contract is about beating with a stick the things that they are doing wrong.... In the contract, there is a lot of emphasis on 'if things go wrong' and less emphasis on 'what we need to do to make sure they do things right'. (Contract Manager-HA)

If MCS do not provide opportunities for positive feedback to the contractors and/or they perceive procedural unfairness in their deployment, this may negatively impact on performance and relationships. In these instances, the partners can rely on trust practices to agree collectively acceptable controls (Minaar et al. 2016). Accordingly, the next section considers how trust practices between the HA and the SPV are developed and utilized to address MCS-related tensions. 


\section{IMPLICATION OF TRUST PRACTICES FOR OPERATIONALIZING GOVERNMENT'S PFI POLICY OBJECTIVES IN THE RCSP}

While the RCSP contract accommodates dispute resolution and joint-membership governance bodies, which could induce trust between the HA and the SPV, this research found that trust practices, such as collaboration and trust-based interaction between the HA and the SPV (and between the latter and sub-contractors), emerged spontaneously in response to contractual tensions. The previous section identified tensions between the HA and the SPV in relation to how the contract specified output and performance expectations. Particularly, it was observed that initially it was difficult for the SPV to align the output requirements with the HA's expectations, resulting in the SPV accumulating considerable performance points. In response, the SPV initiated dialogue with the HA and its sub-contractors to clarify the situation:

When we first started off I think there was a degree of naivety by both parties about how this project would work. Over the months and years, it got progressively better. We would have regular meetings. We talked to them about the dilemmas we faced.... (CEOSPV)

Interviewees indicated that a limitation of PFI was that, since the contracts are drafted ex ante, they could not address all potential uncertainties, unintended consequences and interparty tensions; hence, the control regimes might not facilitate managing such issues when they arise. Therefore, the deployed MCS are unlikely to be aligned with the potential risks and uncertainties:

It is not sufficient if your intent with this contract was to actually wrap everything up in the payment and performance regimes and never revisit them, it is not enough. You know, you need to actually manage it actively.... (Contract Manager-HA) 
Since predicting all possible uncertainties, whether relating to contractors' performance, demand, relationships or handback, is impractical in such long-term contracts, clauses that enable cooperation and re-negotiation are often included (Ross and Yan 2015; Chung 2016). This was evidenced during the field visits, with collaborative dialogue being employed to address contract-related tensions. Indeed, the complexity of defining strategic (outcomebased) objectives, such as improving congestion and road safety, was evident. Here, trust practices over the operational phase facilitated cooperation between the partners to develop (non-contractual) strategies for addressing performance-related ambiguities and complexities contained in the original MCS:

What we found was that there was a complete mismatch between this [pointing to Schedule-18] and this [pointing to a currently developed RCSP KPI document]. What we tried to do was to bring the two together and that is why we created this document which is called the Network Business Plan. It is a practical document and what you can see here is how we look at all the strategic objectives and how we deliver against those on a year-by-year basis. (CEO-SPV)

Such collaboration was viewed positively by the HA, with consultants facilitating riskmanagement dialogue between the HA and the SPV:

I think we have worked hard to build a kind of open dialogue about understanding each other's risks and concerns. We have employed collaboration consultants to help us come up with ways of defining acceptable behaviors.... What we try to do is to identify mutual risks, sort of high risks for one another. Collaboration and trust-building is really important for the visibility of our collective risks... and working jointly trying to resolve those. (Contract Manager-HA)

Lenferink et al. (2013) suggest that real partnership (defined in this research as 'trust practices') between PFI partners could have significant (positive) impacts on project 
outcomes. Such practices could involve adopting non-contractual strategies to manage the project within a complex environment (Steijn et al. 2011). For instance, Chung (2016) highlights that PFI contracts usually omit formal guidance for managing contract closure and asset handback, with their absence posing operational and relational risks.

Contractors expressed the need for regular collaboration with the HA to achieve project objectives since, as discussed previously, their influence over them was limited:

...actually, if I am really going to have an impact on safety I should be working hand-inglove with the Agency.... Similarly, in relation to congestion, the traffic officers there [in the HA], you have to ask yourself why aren't we one team? (CEO-SPV)

Moreover, consistent with Barretta et al. (2008), this research found that rust practices are required not just between the public-sector client and the SPV, but between the latter and subcontractors as their performance could impact the SPV's incentives:

In terms of relationship between us and the O\&M-JV [Operations and Maintenance Joint Venture], there has been a lot of tension because our penalties have largely resulted from their lack of performance. So, we have a new initiative going on. Our goal and objective is to have an alliance programme.... We are also looking at collaborative working on asset management. So that is building bridges and I think it is working very well. (CEOSPV)

With regards to the dis-incentives arising from how payment mechanisms functioned, the public and private sector parties contended that the (original) formulation and operationalization of the payment regimes had delivered unexpected and unintentional results (see previous section:

I think the main thing we didn't get right on these [payment] mechanisms is that we did not test them enough. Did we really want deductions in the first few years on safety mechanism? ...And there are similar issues with the congestion one.... A big issue for us 
is change and change management. I think we should have had in the business case the long-term strategic risks of the Agency and how we intended to manage those with this contract. And in terms of change I think it is just damn hard work. (Contract ManagerHA)

In order to address these anomalies, particularly the SPA, the HA and the SPV negotiated changes to the formulae to incentivize the latter:

We are looking at a strategic change of pay-mech to give them incentives and a bonus to go and do better things about safety and all other things. (Paymech Official-HA)

Accordingly, trust practices involving collaboration, dialogue and the development of non-contractual project governance frameworks were important for the RCSP's strategic management, including whole life-of-contract risk management, and for adjusting MCSrelated anomalies to better incentivize the private sector to deliver the project's objectives. From the public sector's perspective, their participation in trust practices is justified because of the reputational risk associated with service continuity (Shaoul et al. 2012):

What we want is the DBFO-Co to act as we would. We expect from them that level of ownership. And they can only do that if we have a level of mutual understanding. And mutual understanding and trust are similar, not identical. I think mutual understanding is a kind of key point and trust is the next step on from that. (Contract Manager-HA)

The notion that mutual understanding could enable the development of a trust-based relationship in contractual inter-organizational settings is consistent with Minaar et al. (2016). Thus, an interactive review of the contract designed to develop a mutual understanding of each partner's needs could be constitutive of trust practices and contribute to the development of a trusting and collaborative relationship. 


\section{CONCLUDING REMARKS}

Over the past two decades, the use of hybrid models, especially PPPs, has increased globally for delivering public infrastructure projects, particularly roads. However, to date, little is known about the operational dynamics of PPPs, including how accounting controls and interparty trust practices are employed. Internationally, the UK is a lead adopter of PPPs, with PFI being the most well-known. Previous research has focused on the initial stages of PPP, with limited attention given to operational projects (Toms et al. 2011; Andon 2012). In addition, prior research has often criticized the outcome of the operational phase due to contract rigidity in the early phases, with subsequent detrimental consequences for taxpayers (Broadbent et al. 2008; Demirag et al. 2012).

This paper examines how UK road PFI contracts are managed during their operational stages and develops our understanding of MCS and trust practices in achieving contract objectives. From an accounting and public administration perspective, a major theoretical and practical implication of the findings is that, as the UK government's power to govern PFI projects through accounting and MCS may not guarantee the achievement of policy objectives, the enabling mechanism of trust practices is necessary. Indeed, this research indicates that different ideologies and incentives between the parties can be negotiated and reconciled through such practices. Thus, pragmatism can overcome some of the difficulties anticipated in the PPP/PFI literature.

Analysis of the RCSP's performance monitoring practices suggests that accounting provides panoptical mechanisms for the HA to have knowledge of the SPV's performance, thus enabling interventions in situations of under-performance. However, elements relating to original expectations on issues such as availability and safety, which have direct financial consequences on the SPV, functioned bureaucratically and did not provide positive feedback loops. Therefore, such monitoring has limited positive impact on SPV performance. The 
financial incentives, as practiced through the RCSP's payment mechanisms, were also found to cause disincentives for the SPV and tensions with the HA. Firstly, aspects of the payment mechanism did not incentivize the private sector to attain the relevant performance targets for accidents and congestion as the contractors could not fully influence the factors responsible for their achievement. However, when the contractors could influence the underlying project objectives (e.g. managing daytime maintenance), the financial incentives were perceived as effective (e.g. payment mechanism for lane availability). Secondly, payment mechanisms failed to adequately incentivize contractors to pursue long-term strategic performance targets (e.g. implementing safety and congestion-related improvement plans) because the financial reward was deemed inadequate. Thirdly, the payment mechanisms could cause dissonance, particularly if contractors did not perceive that performance is measured and rewarded fairly. In this case, the SPA and PMR were viewed as penalizing the SPV.

Although the RCSP's monitoring and incentive regimes are extensive, as they were deployed in a bureaucratic style they failed to induce trust-based cooperation between the HA and the SPV. This is consistent with Coletti et al. (2005) who argue that the trust-building benefits of MCS may not be experienced without feedback mechanisms. From a policy and practical perspective, while Coletti et al. (2005) contend that a strong MCS may be deployed earlier, this research suggests that control regimes should be employed from contract inception more interactively with opportunities for testing and adaptation. This might reduce MCS costs since early interaction and cooperation could foster a trusting relationship and facilitate the (effective) operation of controls. Clear mechanisms and contractual guidelines for contract re-negotiation could avert substantial (avoidable) costs arising from elaborate arbitration systems (Ross and Yan 2015).

Furthermore, the analysis of the enactment of trust practices suggests that they provide opportunities for the SPV and the HA to revisit certain MCS elements. This is consistent with 
Minnaar et al.'s (2016) assertion that trust can emerge as a 'quasi' actor in interorganizational networks by assigning 'properties of trust' to the contract (MCS in this case). In PFIs, complexity may be imposed by the various players involved in contract design and execution, which could cause mission-misalignment due to multiple (conflicting) objectives. With such complexity, this could raise governance and control challenges for the principal (state), especially given the difficulties involved in terminating a PFI contract and finding alternative contractors (Jupe 2011). Thus, trust practices are essential for sustaining interparty relationships.

This argument is consistent with literature on governance of public-sector networks. Lenferink et al. (2013) assert that dialogue and collaboration between public and private sector partners could span the planning, procurement and post-procurement lifecycles. They contend that this could enable partners to gain continuous insight into each other's mission and issues, leading to trusting relationships. Our findings on how trust practices are used for achieving project objectives are also supported by Steijn et al. (2011), who posit that PFI managerial strategies could have a significant impact on project outcomes. Such strategies involve collaboration, joint working and greater exchange of information (i.e. trust practices), without which it is difficult to achieve desired outcomes (Klijn et al. 2010). Thus, public and private sector PFI contract managers (at least in the UK roads sector) would have to act (additionally) as network managers which could be challenging as UK PFI contracts are typically structured more tightly than their European counterparts (Steijn et al. 2011). This provides interesting research avenues as researchers analyzing the translation of NPM-based MCS within contemporary public-sector networks could study the role of trust practices together with network managers as enablers.

Due to cross-country differences in policy interventions and institutional arrangements for public service delivery, PPPs are disparate (Hodge and Greve 2017). As this RCSP is 
located within the UK's road sector, this may limit the extent to which the findings can be generalized. However, given the limited empirical evidence about the micro-level operational management and relationship practices for these hybrid organizations (Steijn et al. 2011; Andon 2012; Chung 2016), our study provides new insights which could form the basis for further comparative case study research. Investigation of the significance of the performancebased incentives in financial terms is also needed. This is important as PFI investors are reported to have earned high returns (Hellowell and Vecchi 2012). While this research examines the effectiveness of the MCS with respect to achieving the HA's objectives, an analysis of users' (commuters') satisfaction could be conducted. This might facilitate an assessment of whether (and how) PFI can deliver VFM for taxpayers.

\section{REFERENCES}

Alonso, J.M., Clifton, J. and Díaz-Fuentes, D. 2015. 'Did new public management matter? An empirical analysis of the outsourcing and decentralization effects on public sector size', Public Management Review, 17, 643-660.

Andon, P. 2012. 'Accounting-related research in PPPs/PFIs: Present contributions and future opportunities', Accounting, Auditing and Accountability Journal, 25, 876-924.

Barretta, A., Busco, C. and Ruggiero, P. 2008. 'Trust in project financing: An Italian health care example', Public Money and Management, 28, 179-184

Bevan, G. and Hood, C. 2006. 'What's measured is what matters: Targets and gaming in the English public health care system', Public Administration, 84, 517-538.

Broadbent, J. and Laughlin, R. 2005. 'The role of PFI in the UK government's modernisation agenda', Financial Accountability and Management, 21, 75-97. 
Broadbent, J., Gill, J. and Laughlin, R. 2008. 'Identifying and controlling risk: The problem of uncertainty in the private finance initiative in the UK's National Health Service', Critical Perspectives on Accounting, 19, 40-78.

Bryman, A. and Bell. E. 2011. Business Research Methods. Cambridge, New York: Oxford University Press.

Burke, R. and Demirag, I. (2015). 'Changing perceptions on PPP games: Demand risk in Irish roads', Critical Perspectives on Accounting, 27, 189-208.

Busco, C., Riccaboni, A. and Scapens, R. 2006. 'Trust for accounting and accounting for trust', Management Accounting Research, 17, 11-41.

Caperchione, E., Demirag, I. and Grossi, G. (2017). 'Public sector reforms and public private partnerships: Overview and research agenda', Accounting Forum, 41, 1-7.

Chung, D. 2016. 'Risks, challenges and value for money of public-private partnerships', Financial Accountability \& Management, 32, 448-468.

Coletti, A.L., Sedatole, K.L. and Towry, K.L. 2005. 'The effect of control systems on trust and cooperation in collaborative environments', The Accounting Review, 80, 477-500.

Compagni, A., and Tediosi, F. 2012. 'Implementing performance-based funding for health research: When governance and procedural fairness matter', Public Administration, 90, 313-34.

Coulson, A. 2008. 'Value for money in PFI proposals: A commentary on the uk treasury guidelines for public sector comparators', Public Administration, 86, 483-498.

Demirag, I. and Khadaroo, I. 2008. 'Accountability and value for money in private finance initiative contracts', Financial Accountability \& Management, 24, 455-478.

Demirag, I., Khadaroo I. and Stapleton, P. 2010. Public Private Partnership Financiers' Perceptions of Risks. Institute of Chartered Accountants in Scotland. 
Demirag, I., Khadaroo, I., Stapleton, P. and Stevenson, C. 2012. 'The diffusion of risks in public private partnership contracts', Accounting, Auditing and Accountability, 25, 13171339.

Department for Transport (DfT). 2000a. Transport Ten Year Plan 2000. DfT, London.

DfT. 2000b. Tomorrow's roads safer for everyone. DfT, London.

DfT. 2004. The Future of Transport, a network for 2030. DfT, London.

Diefenbach, T. 2009. 'New Public Management in Public sector organizations: The dark sides of managerialistic 'Enlightenment', Public Administration, 87, 892-909.

Edwards, P., Shaoul, J., Stafford, A. and Arblaster, L. 2004. Evaluating the Operation of PFI in Roads and Hospitals. ACCA Research Report 84. The Certified Accountants Educational Trust Limited, London.

Eisenhardt, K.M. and Graebner, M.E. (2007). 'Theory building from cases: Opportunities and challenges'. Academy of Management Journal, 50, 25-32.

English, L. and Baxter, J. 2010. 'The changing nature of contracting and trust in public private partnerships: The case of Victorian PPP prisons', Abacus, 46, 289-319.

European PPP Expertise Centre (EPEC). 2013. Market update: review of the European PPP market - first half of 2013. EPEC, http://www.eib.org/epec/resources.

Florio, M. 2014. 'Contemporary public enterprises: innovation, accountability, governance', Journal of Economic Policy Reform, 17, 201-208

Franco-Santos, M., Lucianetti, L. and Bourne, M. 2012. 'Contemporary performance measurement systems: A review of their consequences and a framework for research', Management Accounting Research, 23, 79-119.

Free, C. 2008. 'Walking the Talk? Supply Chain Accounting and Trust among UK Supermarkets and Suppliers', Accounting, Organisations and Society, 33, 629-662. 
Gerrard, M. 2010. 'Key lessons from PFI', Private Finance International, October 2010. Thomson Reuters, 49-52.

Greenway, J., Salter, B. and Hart, S. 2004. 'The evolution of a 'meta policy': The case of the private finance initiative and the health sector', British Journal of Politics and International Relations, 6, 507-526.

Heald, D. and Steel, D. 2017. 'The governance of public bodies in times of austerity', British Accounting Review, DOI: 10.1016/j.bar.2017.11.001

Hellowell, M. and Vecchi, V. 2012. 'An Evaluation of the Projected Returns to Investors on 10 PFI Projects Commissioned by the National Health Service', Financial Accountability and Management, 28, 77-100.

Her Majesty's Treasury (HMT). 2003. PFI: Meeting Investment Challenge, HMT, London.

HMT. 2007. Standardisation of PFI-contract, version 4, HMT, London.

HMT. 2008. Infrastructure Procurement; delivering long-term value, HMT, London.

HMT. 2012. A New Approach to Public Private Partnerships, HMT, London.

Highways Agency. 2015. Annual report and accounts 2014/15, www.gov.uk/government/publications.

Highways England. 2016. Highways England Annual Report and Accounts 2015-2016: HC 529. Her Majesty's Stationery Office, London.

Hodge, G. and Greve, C. 2017. 'Contemporary public-private partnership: Towards a global research agenda', Financial Accountability and Management, DOI: 10.1111/faam.12132.

Humphrey, C. and Scapens, R.W. 1996. 'Methodological Themes: Theories and Case studies of Organizational Accounting Practices: Limitation or Liberation?', Accounting, Auditing and Accountability Journal, 9, 86-106.

Jupe, R. 2011. 'The modernisation and fragmentation of the UK's transport infrastructure', Financial Accountability and Management, 27, 43-62. 
Khadaroo, I. 2014. 'The valuation of risk transfer in UK school Public Private Partnership contracts', British Accounting Review, 46, 154-65.

Klijn, E.H., Steijn, B. and Edelenbos, J. 2010. 'The impact of network management on outcomes in governance networks', Public Administration, 88, 1063-1082.

KPMG. 2010. PPP procurement: Review of barriers to competition and efficiency in the procurement of PPP projects, KPMG Corporate Finance (Aust) Pty Ltd.

Kurunmäki, L. and Miller, P. 2011. 'Regulatory hybrids: Partnerships, budgeting and modernising government', Management Accounting Research, 22, 220-41.

Lammam, C., MacIntyre, H., Clemens, J., Palacios, M. and Veldhuis, N. 2013. Federal Government Failure in Canada. A Review of the Auditor General's Reports, 1988-2013. Fraser Institute. http://www.fraserinstitute.org/ uploadedFiles/fraser-ca/Content/researchnews/research/publications/federal-government-failure-in-canada-2013.pdf.

Lenferink, S., Tillema, T. and Arts, J. 2013. 'Public-private interaction in contracting: governance strategies in the competitive dialogue of Dutch infrastructure projects', Public Administration, 91, 928-946.

Marques, L., Ribeiro, J.A. and Scapens, R.W. 2011. 'The Use of Management Control Mechanisms by Public Organizations with a Network Coordination Role: A Case study in the Port industry', Management Accounting Research, 22, 269-91.

Meer-Kooistra, J. van d. and Vosselman, E.G.J. 2000. 'Management Control of Inter-firm Transactional Relationships: The Case of Industrial Renovation and Maintenance', Accounting, Organizations and Society, 25, 51-77.

Minnaar, A.R., Vosselman, Ed., van Veen-Dirks, M.G.P. and Zahir-ul-Hassan, M.K. 2016. 'A Relational Perspective on the Contract-Control-Trust Nexus in an Interfirm Relationship', Management Accounting Research, http://dx.doi.org/10.1016/j.mar.2016.07.003. 
National Audit Office (NAO). 1998. The Private Finance Initiative: The first four Design, Build, Finance and Operate Roads Contract. NAO, London.

NAO. 2006. A framework for evaluating the implementation of Private Finance Initiative projects: Volume 2. NAO, London.

NAO. 2009. Private Finance Projects, (A paper for the Lords Economic Affairs Committee, October 2009). NAO, London

NAO. 2010. Procurement of the M25 Private-Finance Contract. NAO, London.

Nisar, T. 2017. 'Value for money drivers in public private partnership schemes', International Journal of Public Sector Management, 20, 147-156.

Public Works Financing. 2011. International Major Projects Survey, Public Works Financing. October, Vol. 264.

Robson, K. 1992. 'Accounting Numbers as 'Inscription': Action at a Distance and the Development of Accounting', Accounting, Organizations and Society, 17, 685-708

Ross, T.W. and Yan, J. 2015. 'Comparing public-private partnerships and traditional public procurement: Efficiency vs. flexibility', Journal of Comparative Policy Analysis: Research and Practice, 17, 448-466.

Sclar, E. 2001. You don't always get what you pay for: The economics of privatization. Cornell University Press.

Sclar, E. 2015. 'The political economics of investment Utopia: public-private partnerships for urban infrastructure finance', Journal of Economic Policy Reform, 18, 1-15.

Shaoul, J., Stafford, A. and Stapleton, P. 2006. 'Highway robbery? A financial analysis of design, build, finance and operate (DBFO) in UK roads', Transport Reviews, 26, 257274. 
Shaoul, J., Stafford, A., and Stapleton, P. 2007. 'Evidence-based policies and the meaning of success: The case of a road built under design build finance and operate (DBFO)', Evidence and Policy: A Journal of Research, Debate and Practice, 3, 159-79.

Shaoul, J., Stafford, A. and Stapleton, P. 2012. 'Accountability and corporate governance of public private partnerships', Critical Perspectives on Accounting, 23, 213-229.

Speklé, F.R. and Verbeeten, H.M.F. 2014. 'The Use of Performance Measurement systems in the Public Sector: Effects on Performance', Management Accounting Research, 25, 131146.

Spence, L.J. and Rinaldi, L. 2014. 'Governmentality in Accounting and Accountability: A case study of Embedding Sustainability in a Supply chain', Accounting, Organizations and Society, 39, 433-452.

Steijn, B., Klijn, E.H. and Edelenbos, J. 2011. 'Public private partnerships: Added value by organizational form or management?', Public Administration, 89, 1235-1252.

Toms, S., Beck, M. and Asenova, D. 2011. 'Accounting, Regulation and Profitability: The Case of PFI Hospital Refinancing', Critical Perspectives on Accounting, 22, 668-681.

Walker, S. 2016. 'Revisiting the Roles of Accounting in Society', Accounting, Organizations and Society, 49, 41-50.

Warner, M.E. and Bel, G., 2008. 'Competition or monopoly? Comparing privatization of local public services in the US and Spain', Public Administration, 86, 723-735.

Yehoue, B. E., 2013. 'Financial and Sovereign Debt crises and PPP Market structure', in: Vries, P. and Yehoue, B.E., (Eds.), The Routledge Companion to Public-Private Partnerships. Routledge, 349-370.

Yin, K.R. 2017. Case study research and applications: Design and methods. Sage Publications. 


\section{Notes}

${ }^{a}$ Internationally PFI-type models are also termed Privately Financed Projects (PFPs) or Public Private Partnerships (PPPs or P3). This paper uses the UK-specific term, PFI. This is a long-term arrangement whereby a government department acquires (through competitive bidding) construction services for public infrastructure (e.g. a road), together with post-construction maintenance and services, from the private sector under a single contract in return for unitary payments linked to the latter's performance under the contract. PFI procurements are mainly privately financed, with contracts typically for 25-30 years (Her Majesty's Treasury 1995, 2008).

${ }^{\mathrm{b}}$ In 1994, the UK government established the HA as an executive agency of the Department for Transport with responsibility for the construction and maintenance of England's strategic road network. In April 2015, the HA became a government company, 'Highways England'. Existing PFI assets and liabilities (including this RCSP) were transferred to the newly-formed company (Highways England 2016).

${ }^{\mathrm{c}}$ Throughout this paper, such control regimes are referred to as MCS (management control systems), including those deployed by a government department within public-sector networks to control service-delivery organizations with the purpose of influencing the latter's behavior in order to achieve desirable or predetermined outcomes (Marques et al. 2011).

${ }^{\mathrm{d}}$ As stated in official reports, which cannot be cited for confidentiality reasons.

e Which cannot be cited for confidentiality reasons.

${ }^{\mathrm{f}}$ As elements of these documents were redacted, including the financial values related to the payment mechanism, it was not possible to analyze the payment-based incentives from a financial perspective.

${ }^{\mathrm{g}}$ Key Performance Indicators.

${ }^{\mathrm{h}}$ Figure B illustrates the KPIs for the RCSP's primary project objectives of reducing congestion and improving road safety. These KPIs were selected through the analysis of the RCSP's Business Case and Schedule-18, on the basis of:

- the significance of the KPIs in relation to the government's strategic goals of improving safety and reducing congestion (Department for Transport 2000a, b, 2004); and

- $\quad$ ensuring that the associated incentive regimes for the (selected) KPIs have been fully operational since the commencement of the project.

i The partnering organization expects to gain an economic or strategic benefit from cooperating (Marques et al. 2011).

${ }^{\mathrm{j}}$ If the partnering organization does not cooperate it will receive sanctions or penalties (Marques el al. 2011).

k In older HA road PFI contracts, these were called 'penalty points'. During the interviews, it transpired that the term was changed to avoid any negativity associated with the word 'penalty'.

${ }^{1}$ Route performance was not operationalized at the time of this research due to technical difficulties with the equipment.

${ }^{\mathrm{m}}$ Killed or seriously injured. 


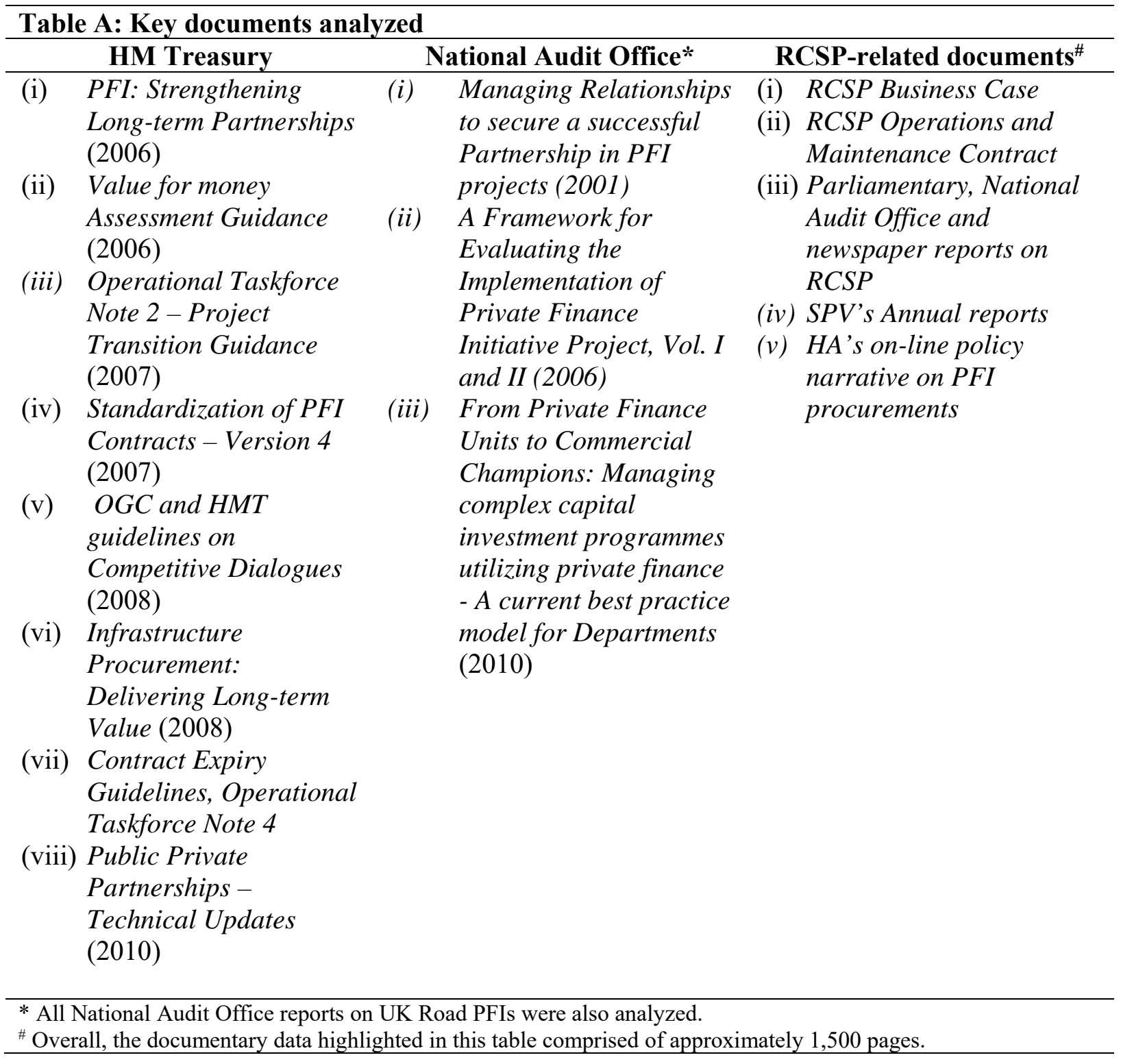


Figure A: A representation of MCS (outcome controls) in the RCSP

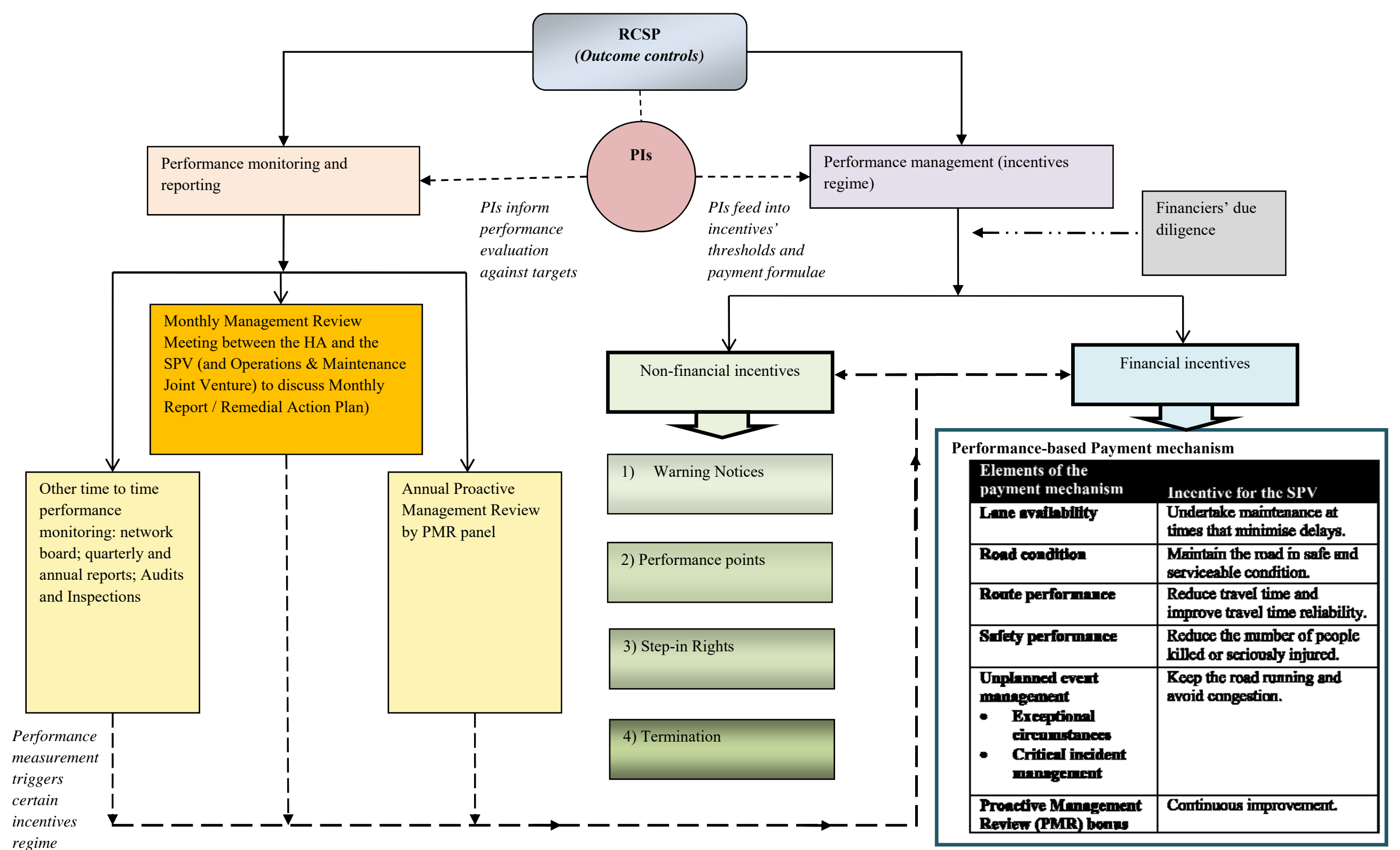




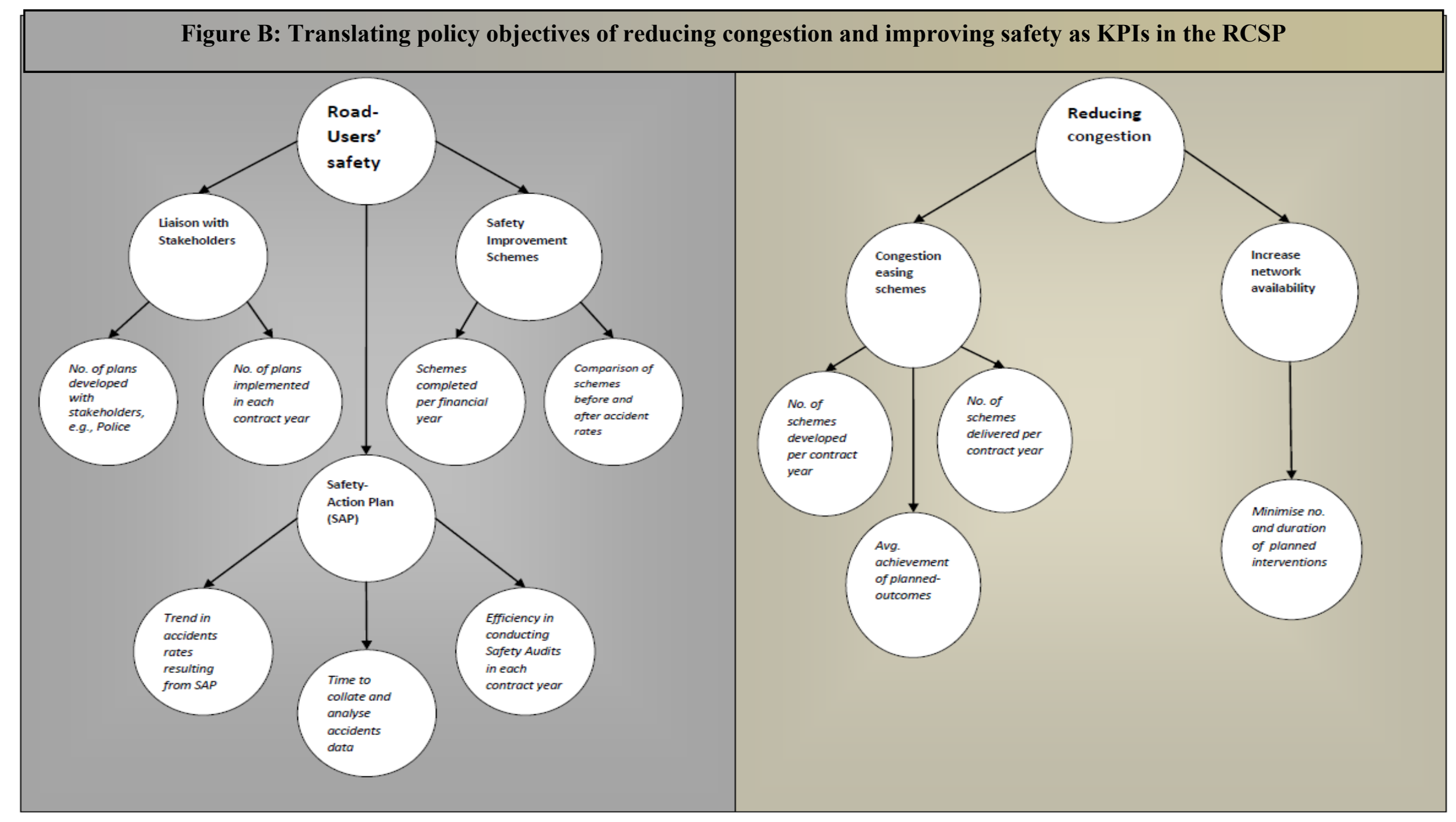

Source: Developed from RCSP (Operations and Maintenance) Contract, Schedule-18 